\title{
Type 1 versus type 2 fuzzy logic speed controllers for brushless DC motors
}

\author{
Hayder Yousif Abed, Abdulrahim Thiab Humod, Amjad J. Humaidi \\ Department of Electrical Engineering, University of Technology, Baghdad, Iraq
}

\begin{tabular}{|c|c|}
\hline Article Info & ABSTRACT \\
\hline Article history: & \multirow{6}{*}{$\begin{array}{l}\text { This work presented two fuzzy logic (FL) schemes for speed-controlled } \\
\text { brushless DC motors. The first controller is a Type } 1 \text { FL controller (T1FLC), } \\
\text { whereas the second controller is an interval Type } 2 \text { FL controller (IT2FLC). } \\
\text { The two proposed controllers were compared in terms of system dynamics } \\
\text { and performance. For a fair comparison, the same type and number of } \\
\text { membership functions were used for both controllers. The effectiveness of } \\
\text { the structures of the two FL controllers was verified through simulation in } \\
\text { MATLAB/SIMULINK environment. Simulation result showed that IT2FLC } \\
\text { exhibited better performance than T1FLC. }\end{array}$} \\
\hline Received Mar 26, 2019 & \\
\hline Revised Jul 23, 2019 & \\
\hline Accepted Aug 29, 2019 & \\
\hline Keywords: & \\
\hline BLDC motor & \\
\hline
\end{tabular}

FL type 1

Interval FL type 2

Speed control

Copyright $\odot 2020$ Institute of Advanced Engineering and Science. All rights reserved.

Corresponding Author:

Hayder Yousif Abed,

Department of Electrical Engineering,

University of Technology,

Baghdad, Iraq.

Email: 10990@uotechnology.edu.iq

\section{INTRODUCTION}

Brushless DC (BLDC) motors can be used in several fields and applications, such as industrial automated electric vehicles and aerospace computers. BLDC motors exhibit several advantages over brushed DC motors. They are characterised by low maintenance due to commutator disposal, long operating life due to lack of friction and electrical losses and high power density [1, 2]. The BLDC motors have no brushes, which prolongs the life time of motor and avoids their maintenance. Additionally, these motors are characterized by high electromagnetic torque-to-weight ratio, which make them suitable for most application $[2,3]$. Compared with brushed DC motors and induction machines, BLDC motors have lower inertia that enables faster dynamic response to reference commands. In addition, they are more efficient due to the permanent magnets that can perform with virtually zero rotor losses [3-5].

BLDC motors have a complex and nonlinear model. To overcome the control problem, a nonlinear fuzzy logic controller (FLC) is used to control the speed of a BLDC motor. This intelligent controller has a simple structure and is relatively easy to implement due to its modest fuzzy rule in the rule base [6, 7]. Recently, the intelligent control of BLDC motors has elicited the attention of many researchers. A review of the most relevant studies is presented in this paper. R. Arulmozhiyal and R. Kandiban compared a conventional proportional-integral-derivative (PID) controller and a fuzzy PID controller in terms of the speed control of BLDC motors. The results were obtained using MATLAB/SIMULINK and then experimentally verified.The simulated and practical results showed that the fuzzy PID.

Controller outperformed the conventional PID controller [8]. E. Blessy and M. Murugan analysed a BLDC motor model and designed an FLC to improve the dynamic performance of speed control. They compared the fuzzy logic (FL), proportional, proportional-integral and PID controllers to evaluate the impact of each controller on speed dynamic performance [9]. Mohammed A. Shamseldin and Adel A. 
EL-Samahy presented three different robust controllers for the speed regulation and tracking control of highperformance BLDC motors. These controllers are conventional PID, genetic-based PID and self-tuning fuzzy PID controllers. Genetic optimisation and self-tuning intend to find the best gains of PID controllers in terms of transient and steady-state characteristics. Their work showed that the self-tuning fuzzy PID controller outperformed the other control techniques [10]. P. Hari Krishnan and M. Arjun developed an adaptive FL PID controller to control the speed of a BLDC motor. They compared the fuzzy PID controller and the adaptive fuzzy PID controller. The simulation results based on MATLAB/SIMULINK showed that the adaptive fuzzy PID controller exhibited better performance than the fuzzy PID controller [11].

Akhila M. and Ratnan P. introduced an adaptive neuro-based fuzzy (ANFIS) controller for electric vehicles based on BLDC motors. They adopted a regenerative braking strategy to maintain the vehicle's stability and recover energy, thereby reducing air pollution and achieving optimum energy utilisation. The simulation in MATLAB showed that the ANFIS-based controller could rapidly reach the target and overcome the complexity of the problem [12]. Shu Xiong et al. developed a radial basis function (RBF) neural network with a PID controller to overcome the response lag, low precision and instability problems due to the use of the classical PID controller in the speed control of BLDC motors. The simulation results showed that the proposed intelligent controller could effectively improve the performance of the controlled system and provide faster response than the traditional PID controller [13]. Muhammed A. Ibrahim etal submitted an optimal control design of Brushless DC motor speed control based on genetic algorithm (GA). The optimization method is employed to find optimal values of Proportional-Integral-Derivative (PID) parameters in terms of better dynamic performance [14]. N. N. Baharudin and S. M. Ayob ustilized hybrid conventional and intelligent controller to cope with the drawback of both controllers. The conventional controller is represented by linear controllers such as PI, PID and PD controller, while the intelligent controller is designed based on FL control [15].

One main issue in control of BLDC motor is how to design a controller such as to obtain high dynamic performance and to cope with system uncertainity and load disturbance. The conventional controller lacks the ability to give satisfactory responses under parameter variation and load application. Therefore, FL controller is proposed to replace the classical controllers to solve the degrade in system performance due to uncertainity in system paramters. The present work compares a Type 1 FLC (T1FLC) and an interval Type 2 FLC (IT2FLC) for the speed control of BLDC motors. The performance of each controller is assessed in terms of transient and steady-state characteristics. Their performance is evaluated in MATLAB.

\section{DYNAMIC MODEL OF A BLDC MOTOR}

A BLDC motor is a three-phase, star-connected, four-pole, trapezoidal back electromotive force (EMF) type with a three-phase inverter. Figure 1 shows the basic block diagram of the speed control for a BLDC motor.

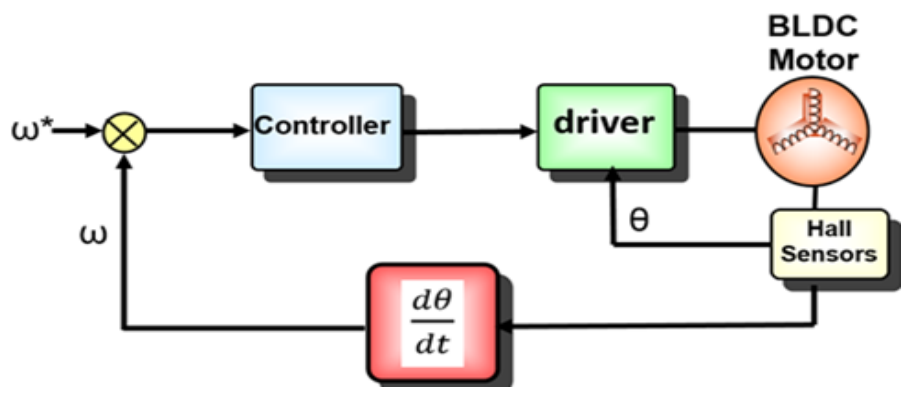

Figure 1. Basic block diagram of the sensor-less drive of a BLDC motor

The The voltage equations for a BLDC motor can be described by the following set of equations [3, 12]:

$$
\begin{aligned}
& v_{a}=R_{a s} i_{a}+L_{a a} \frac{d}{d t}\left(i_{a}\right)+L_{a b} \frac{d}{d t}\left(i_{b}\right)+L_{a c} \frac{d}{d t}\left(i_{c}\right)+e_{a s} \\
& v_{b}=R_{b s} i_{b}+L_{b a} \frac{d}{d t}\left(i_{a}\right)+L_{b b} \frac{d}{d t}\left(i_{b}\right)+L_{b c} \frac{d}{d t}\left(i_{c}\right)+e_{b s} \\
& v_{c}=R_{c s} i_{b}+L_{c a} \frac{d}{d t}\left(i_{a}\right)+L_{c b} \frac{d}{d t}\left(i_{b}\right)+L_{c c} \frac{d}{d t}\left(i_{c}\right)+e_{c s}
\end{aligned}
$$


where $v_{a}, v_{b}$ and $v_{c}$ are the stator phase voltages; $R_{a}, R_{b}$ and $R_{c}$ are the phase resistances of the stator; $i_{a}, i_{b}$ and $i_{c}$ are the currents of the stator phases; $L_{a a}, L_{b b}$ and $L_{c c}$ are the self-inductances of the stator windings; $L_{a b}, L_{b c}, L_{b a}, L_{a c}, L_{c a}$ and $L_{c b}$ are the mutual inductances amongst the stator windings and $E_{a}, E_{b}$ and $E_{c}$ are the back EMFs of the three phase stators $[3,12]$. Given the symmetric structure and equal resistances of the three stator windings, we derive

$$
\begin{aligned}
& L_{a a}=L_{b b}=L_{c c}=L \\
& L_{a c}=L_{a b}=L_{b a}=L_{b c}=L_{c a}=L_{c b}=M
\end{aligned}
$$

where $L$ is the self-inductance of the stator and $\mathrm{M}$ is the mutual inductance. $\mathrm{L}$ and $\mathrm{M}$ are independent of the rotor position. The three-phase star winding motor can be expressed as follows:

$$
\begin{aligned}
& i_{a}+i_{b}+i_{c}=0 \\
& M i_{a}+M i_{b}+M i_{c}=0
\end{aligned}
$$

The instantaneous induced EMFs can be described by

$$
\begin{aligned}
& e_{a t s}=f_{a s}\left(\theta_{r}\right) \lambda_{p} \omega_{m} \\
& e_{b t s}=f_{b s}\left(\theta_{r}\right) \lambda_{p} \omega_{m} \\
& e_{c t s}=f_{c s}\left(\theta_{r}\right) \lambda_{p} \omega_{m}
\end{aligned}
$$

where $\omega_{m}$ is the rotor angular speed and $\theta_{r}$ is the rotor position. The complete model for a BLDC motor can be written in matrix form using (1), (2) and (3) as follows [16]:

$$
\left(\begin{array}{l}
v_{a} \\
v_{b} \\
v_{c}
\end{array}\right)=\left(\begin{array}{ccc}
R_{s} & 0 & 0 \\
0 & R_{s} & 0 \\
0 & 0 & R_{s}
\end{array}\right)\left(\begin{array}{l}
i_{a} \\
i_{b} \\
i_{c}
\end{array}\right)+\left(\begin{array}{ccc}
L_{a a} & L_{a b} & L_{a c} \\
L_{b a} & L_{b b} & L_{b c} \\
L_{c a} & L_{c b} & L_{c c}
\end{array}\right) \frac{d}{d t}\left(\begin{array}{l}
i_{a} \\
i_{b} \\
i_{c}
\end{array}\right)+\left(\begin{array}{l}
e_{a s} \\
e_{b s} \\
e_{c s}
\end{array}\right)
$$

All phase resistances are equal and can be designated by $(\mathrm{R})$ because a balanced three-phase motor is considered. Therefore, (11) can be written as follows:

$$
\left(\begin{array}{l}
v_{a} \\
v_{b} \\
v_{c}
\end{array}\right)=\left(\begin{array}{ccc}
R & 0 & 0 \\
0 & R & 0 \\
0 & 0 & R
\end{array}\right)\left(\begin{array}{l}
i_{a} \\
i_{b} \\
i_{c}
\end{array}\right)+\left(\begin{array}{ccc}
L-M & 0 & 0 \\
0 & L-M & 0 \\
0 & 0 & L-M
\end{array}\right) \frac{d}{d t}\left(\begin{array}{l}
i_{a} \\
i_{b} \\
i_{c}
\end{array}\right)+\left(\begin{array}{l}
e_{a} \\
e_{b} \\
e_{c}
\end{array}\right)
$$

where functions $f_{a s}\left(\theta_{r}\right), f_{b s}\left(\theta_{r}\right)$ and $f_{c s}\left(\theta_{r}\right)$ have the same shape as $e_{a t s}, e_{b t s}$ and $e_{c t s}$ with a maximum magnitude of \pm 1 . In addition, the induced EMFs have rounded edges rather than sharp corners as observed in the trapezoidal functions. This condition is attributed to the time derivative of the flux linkages. The flux density functions are smooth without sudden edges because the flux linkages are fringing and continuous functions. The expression for electromagnetic torque can be written as

$$
\begin{aligned}
& T_{e}=\frac{e_{a} i_{a}+e_{b} i_{b}+e_{c} i_{c}}{\omega} \\
& E_{p}=\lambda_{p} \omega_{m}
\end{aligned}
$$

The developed torque is used to overcome the mechanical rotation and load torque, which is expressed as:

$$
T_{e}=J \frac{d \omega}{d t}+B_{f} \omega_{m}+T_{L}
$$

\section{TYPE-1 FLC AND TYPE-2FLC (T1FLC, T2FLC)}

The design of a fuzzy logic controller requires the choice of membership functions. The membership functions should be chosen such that they cover the whole universe of discourse. It should be taken care that the membership functions overlap each other. This is done in order to avoid any kind of 
discontinuity with respect to the minor changes in the inputs $[17,18]$. T2FLC consists of a set of membership functions (MFs) that operate with 3D uncertainties, whereas the MFs of type 1 fuzzy sets operate with only two dimensions. The fuzzy sets of MFs are shown in Figure 2. These fuzzy sets are capable of modelling and handling uncertainties, nonlinearities and linguistic variables related to the input and output of FLCs by modelling them and reducing their effectiveness. T1FLC fuzzy sets supplement classical fuzzy sets, thereby clearly indicating the preferences of IT2FLC [19].

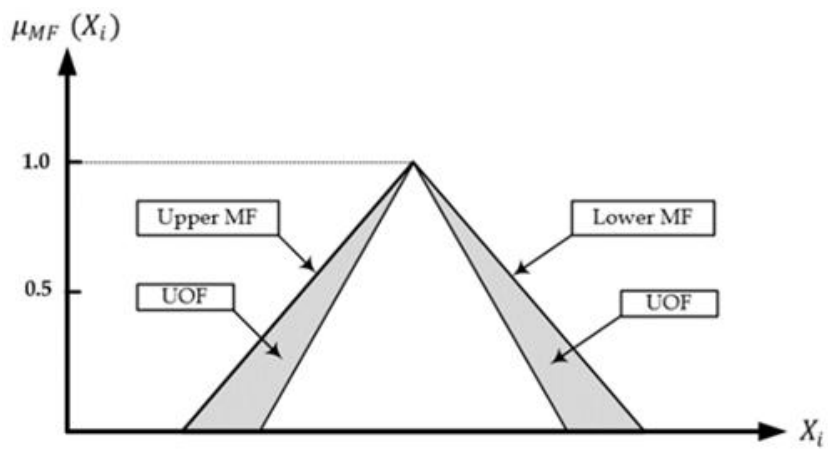

Figure 2. Interval fuzzy type 2 MF structure

The mathematical equation for a system is required to control practical systems based on the traditional control design. Most system equations that describe system dynamics are differential equations associated with either continuous or discrete time systems. In reality, most physical systems are complex and nonlinear. An accurate nonlinear model is difficult to develop for most systems. Although a relatively exact model can be derived, designing a controller that can achieve the required dynamics is too complex, particularly for traditional control designs that impose certain assumptions on a system (e.g. system linearity). The advantages of T2FLCs over T1FLCs can be summarised as follows [20-23]:

a. T2FLCs are more robust than T1FLCs because they can work under a wider range of operating conditions than T1FLCs. In addition, T2FLCs can deal with noise and load changes in a plant.

b. The fuzzy sets and MFs of T2FLCs are fuzzy. Moreover, the uncertainty can handle and model numerical uncertainties, nonlinearities and linguistic variables that are accompanied by the inputs and output of the universe of discourse (UOD) for FLCs.

c. The uncertainty of type 2 fuzzy sets can adopt the same UOD as that of type 1 fuzzy sets but with a smaller number of labels.

The following definitions describe the basic mathematical concepts for T2FLCs [24, 25].

Definition 1. If $\tilde{A}$ denotes type 2 fuzzy sets, which is characterised by MF $u_{\tilde{A}}(x . u)$, where $x \subset X, X$ is the $\mathrm{UOD}$ and $u \in J_{x} \subseteq[0.1]$; then

$$
\tilde{A}=\left\{\left((x \cdot u) \cdot \mu_{\tilde{A}}(x \cdot u)\right) \mid x \in X . u \in J_{x} \subseteq[0.1]\right\}
$$

where $0 \leq u_{\tilde{A}}(x . u) \leq 1$. The equation can be expressed as

$$
\tilde{A}=\int_{x \in X} \int_{u \in J_{x}} \frac{\mu_{\widetilde{A}}(x . u)}{(x . u)} J_{x} \subseteq[0.1]
$$

where $\iint$ represents the union over all admissible $u$ and $x$.

Definition 2. A $2 \mathrm{D}$ system with axes $u$ and $u_{\tilde{A}}(x . u)$ is known as the vertical slice of $u_{\tilde{A}}(x . u)$, which is represented as

$$
\mu_{\tilde{A}}\left(x=x_{1} \cdot u\right)=\mu_{\tilde{A}}=\int_{u \in J_{x}} \frac{\mu_{\widetilde{A}}(x \cdot u)}{(x \cdot u)} J_{x 1} \subseteq[0.1]
$$

where $0 \leq f_{x 1}(u) \leq 1$ and $\mu_{\tilde{A}}(x)$ is defined as the secondary MF and secondary set, respectively. The primary MF of $x_{1}$ is designated by $J_{x 1}$ and is the domain of the secondary membership, where $J_{x 1} \subseteq[0.1]$ for all $x_{1}$ in $\mathrm{X}$. 
Definition 3. The amplitude of the secondary MF is defined as the second degree, which is referred to as the secondary grade.

Definition 4. The bounded area of uncertainty for type 2 fuzzy set $\tilde{A}$ is called the footprint of uncertainty (FOU). FOU defines the union of all primary MFs, which can be described as

$$
\operatorname{FOU}(\tilde{A})=U_{x \in X} J_{x}
$$

Definition 5. The upper and lower MFs of $\tilde{A}$ are two type 1 fuzzy sets, where the boundaries of $F O U(\tilde{A})$ for type 2 fuzzy sets $\tilde{A}$ are the lower and upper bounds of type 1 fuzzy sets. The lower MF is described as $\underline{\tilde{\mu}_{\tilde{A}}}(x) x \in X$ and the upper MF is defined as $\widetilde{\tilde{\mu}}_{\tilde{A}}(x) x \in X$, which indicate that

$$
\begin{aligned}
& \overline{\tilde{\mu}_{\tilde{A}}}(x)=\overline{\operatorname{FOU}(\tilde{A})}, \\
& \underline{\tilde{\mu}_{\tilde{A}}}(x)=\underline{\operatorname{FOU}(\tilde{A})} .
\end{aligned}
$$

The lower and upper MFs frequently exist because the domain of the secondary MFs is limited within the range of $[0,1]$. The structure of the interval type 2 FL membership of MF with its secondary MFs is shown in Figure 3.

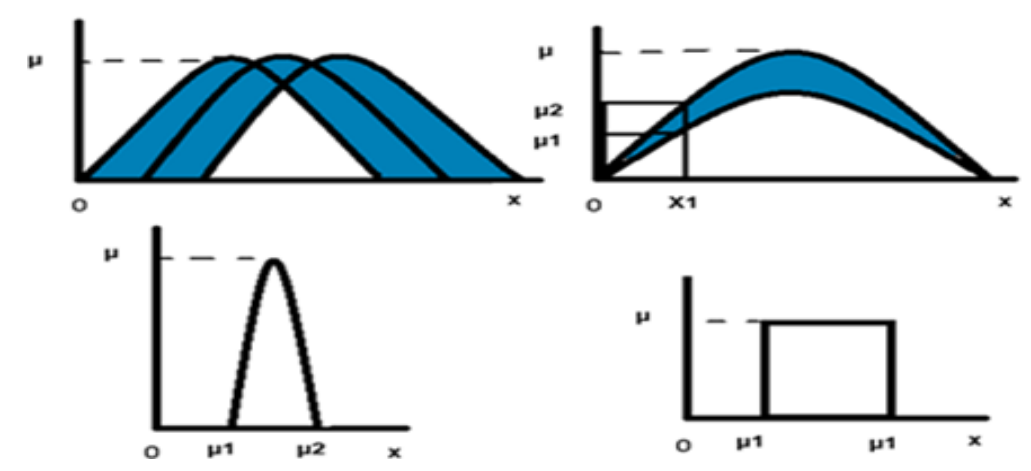

Figure 3. Interval fuzzy type 2 MF structure with its secondary MFs

\section{SIMULATION RESULTS}

In The effectiveness of T1FLC and T2FLC for the speed control of BLDC motors is verified through simulation in MATLAB/SIMULINK (R2017b) environment. The SIMULINK modelling of FLCbased speed control is shown in Figure 4. The BLDC motor parameters used throughout the simulation are listed inTable 1.

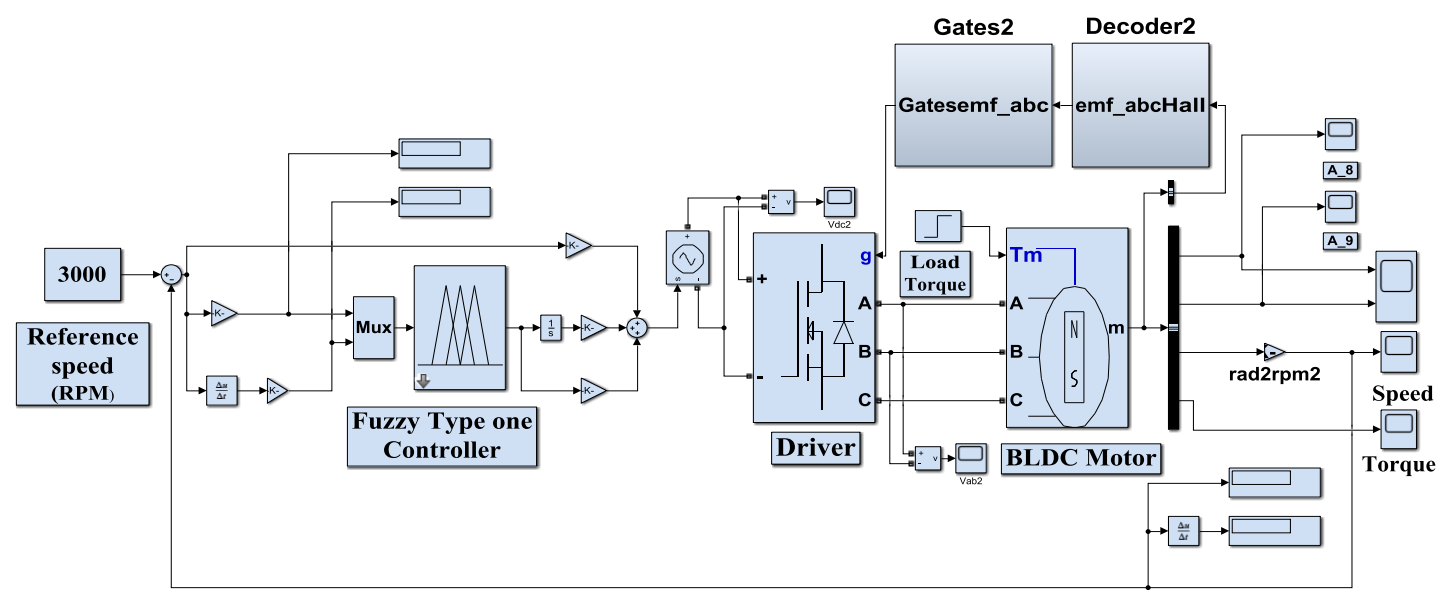

Figure 4. BLDC motor with T1FLC 
Table 1. Parameters of BLDC motor

\begin{tabular}{ll}
\hline Motor Parameters & Values \\
\hline Number of poles & 8 \\
Number of phases & 3 \\
Stator Resistance & $0.7 \Omega$ \\
Stator Inductance & $0.5 \times 10^{-3} \mathrm{H}$ \\
Rated power of motor & $92 \mathrm{Watt}$ \\
Rated speed of motor & $3000 \mathrm{RPM}$ \\
Rated torque of motor & $0.22 \mathrm{~N} . \mathrm{m}$ \\
Rotor inertia of motor & $0.0075 \times 10^{-3} \mathrm{Kg} . \mathrm{m}^{2}$ \\
\hline
\end{tabular}

The MFs of T1FLC for error and change of error is shown in Figure 5 and the MF of FL output is depicted in Figure 6. Figure 7 presents the speed response due to T1FL and IT2FL controllers. The performance evaluation of T1FLC and T2FLC is performed in terms of the dynamic response and steadystate characteristics of the controlled motor. The best controller is the one that provides the minimum peak overshoot $\mathrm{M}_{\mathrm{p}}$, minimum rise time $\mathrm{T}_{\mathrm{r}}$ and minimum steady-state error $e_{s s}$. It is clear in the figure that IT2FL controller shows better transient charctersitics than T1FL controller. Table 2 lists the numerical evaluation of transient paramters for both controllers. The load rejection capability of both controllers can also be deduced from Figure 7. The figure shows a load of $0.4 \mathrm{~N} \cdot \mathrm{m}$ is applied to the motor at $0.06 \mathrm{~s}$. It evident from the zoomed figure that the response suffers no change in case of IT2FL controller, while a dip of maximum 60 RPM has been observed in case of T1FL controller. This indicates that IT2FL controller has better load rejection capability than T1FL controller. Figure 8 shows the behavior of currents generated by both controllers. It evident from the Figure 8 that the current due to IT2FL controller has less excursion level than that generated by T1FL controller.

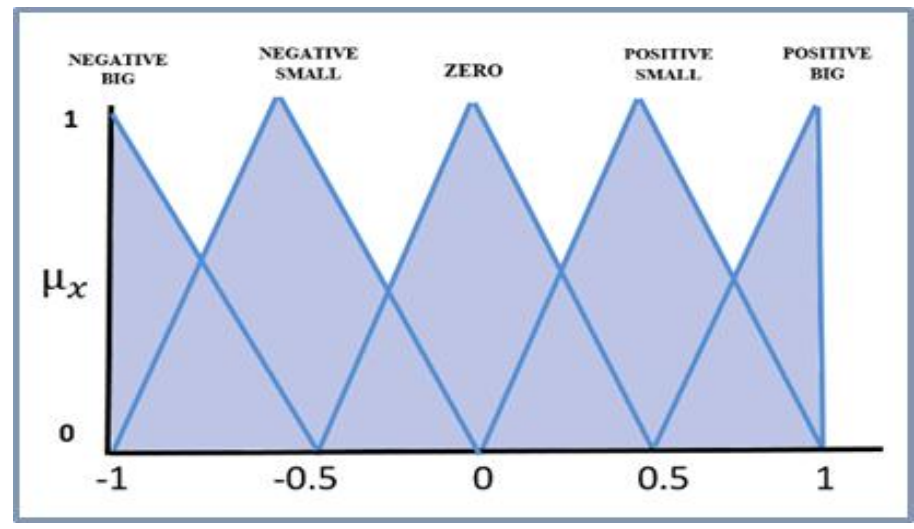

Figure 5. MFs of the error and change of error of T1FLC

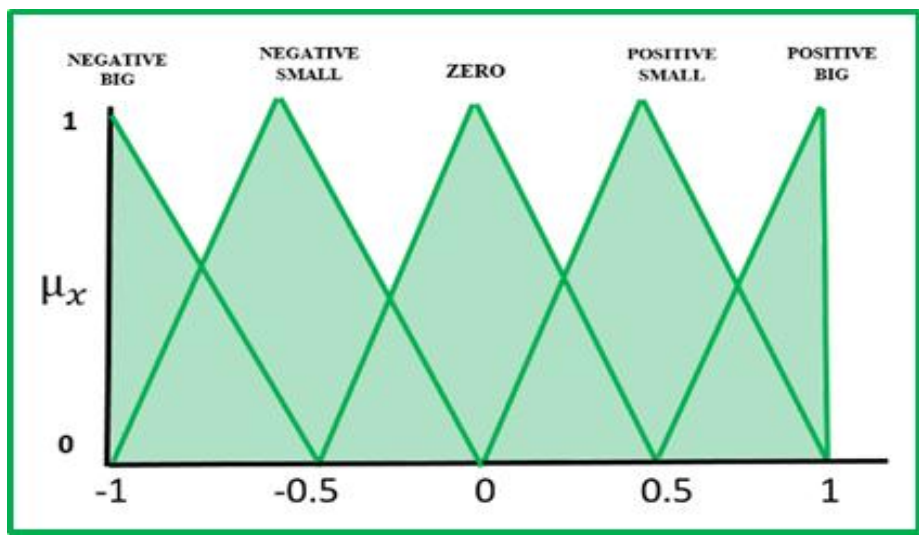

Figure 6. MFs of the output of T1FLC 


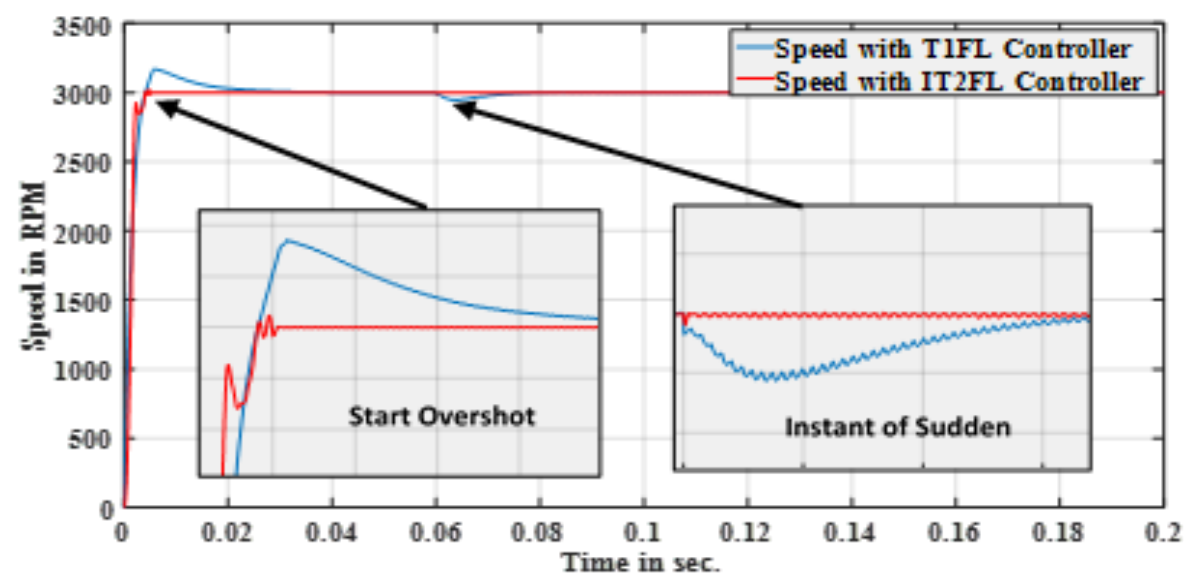

Figure 7. Dynamic responses due to T1FL and ITFL controllers under disturbance application

Table 2. Comparison of speed control between different controllers for a BLDC motor

\begin{tabular}{ccc}
\hline Characteristics of Dynamic Response & \multicolumn{2}{c}{ Types of Controllers } \\
& Type-1 FLC & Type-2 FLC \\
\hline Rising Time (Tr) Sec & $3.34 \times 10^{-3}$ & $3.12 \times 10^{-3}$ \\
Maximum Overshoot (Mp) & 277 & 11 \\
Steady-state error (ESS) rad/sec. & 4.3797 & 1.6193 \\
Settling Time (Ts) Sec. & $12.9 \times 10^{-3}$ & $3.2 \times 10^{-3}$ \\
\hline
\end{tabular}

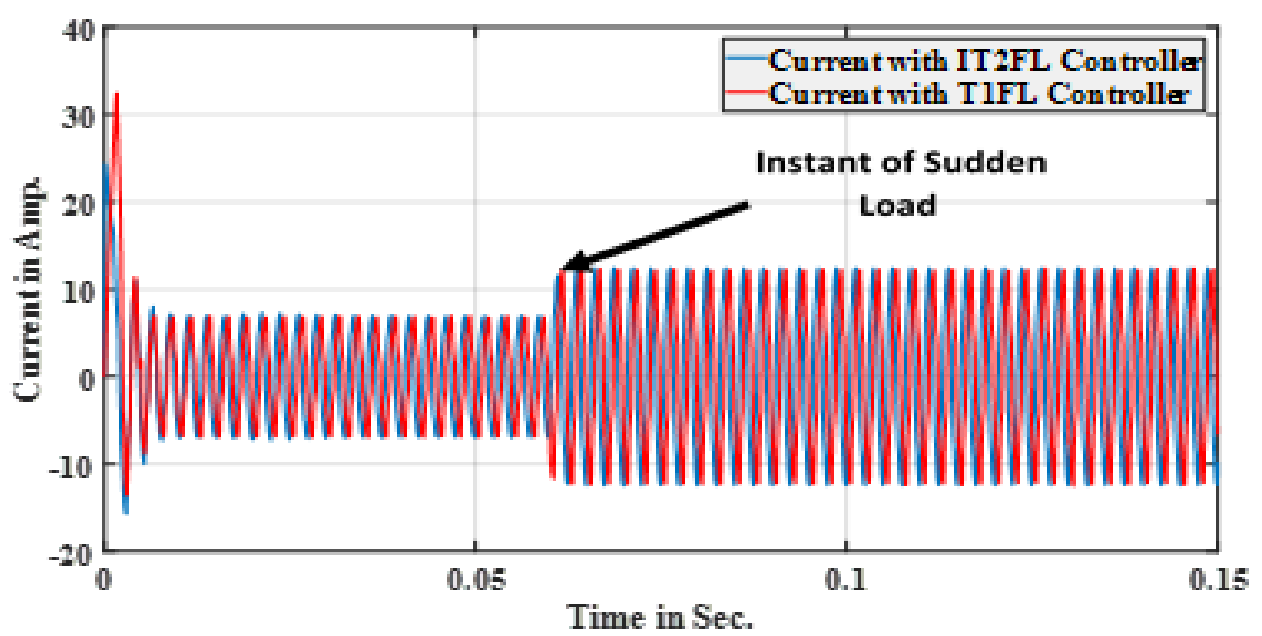

Figure 8. Current of phase A when T1FL and T2FL controllers are used

The response of back EMF is shown in Figure 9. Where a voltage dip is observerd at the instant when the load is applied. T2FLC can succesfully regain the voltage magnitude to its value before load change. The result of the motor electrical torque that is produced in the air gap between the rotor and the stator is shown in Figure 10. The value of the motor electrical torque is increased at the instant when the load is applied. Compared with the result presented in Figure 10, the motor electrical torque is proportional to the stator current of the BLDC motor. Another simulation is performed for the operation of BLDC using IT2FLC, as shown in Figure 11. An M-file code is written and inserted into the simulation rather than utilising the FLC tool box for T1FLC. 


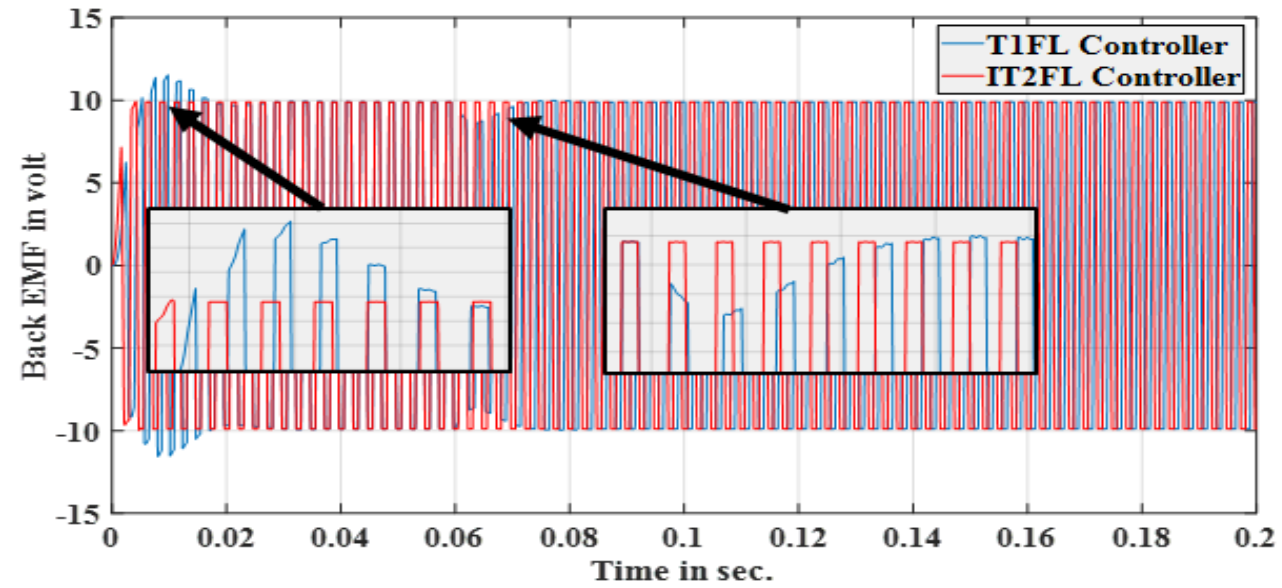

Figure 9. Back EMF of the motor based on T1FL controller and IT2FL controller

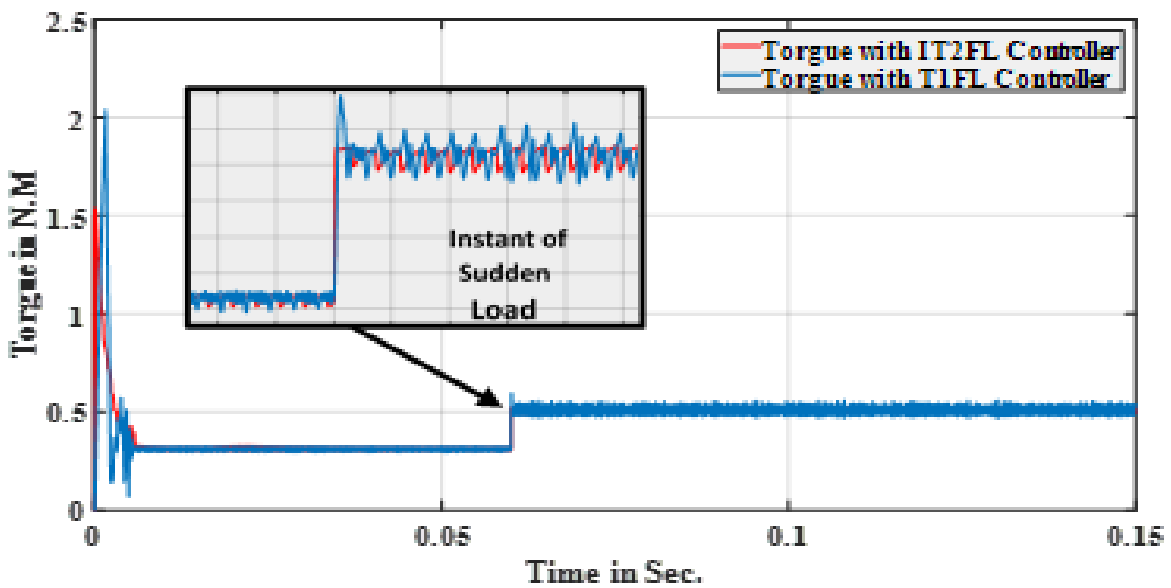

Figure 10. Electrical torque of the motor when T1FL controller and IT2FL controller are used

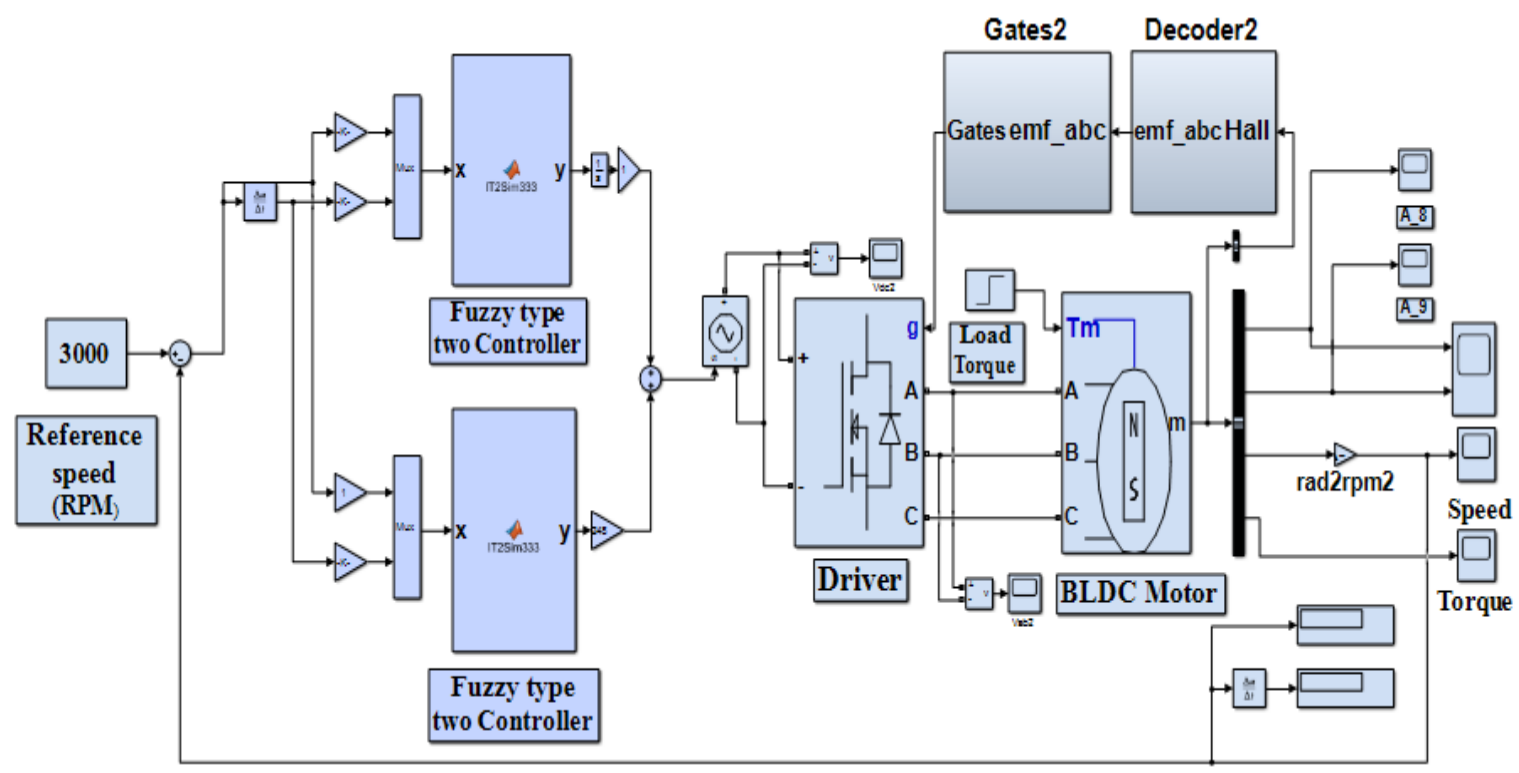

Figure 11. BLDC motor with T2FLC 


\section{CONCLUSIONS}

This study compares two types of FL structure, namely, T1FLC and IT2FLC, for controlling the speed of BLDC motors. The performance evaluation is verified through simulation in MATLAB/SIMULINK. The performance of the controllers is based on transient and steady-state characteristics. The simulation results and performance table show that IT2FLC outperforms T1FLC in terms of transient and steady-state parameters.

\section{REFERENCES}

[1] Prasad, et al., "An intelligent fuzzy sliding mode controller for a BLDC motor," 2017 International Conference on Innovative Mechanisms for Industry Applications (ICIMIA), pp. 274-278, 2017.

[2] Yusnida Tarmizi, Auzani Jidin, Kasrul Abdul Karim and Tole Sutikno, "A simple constant switching frequency of direct torque control of brushless DC motor," International Journal of Power Electronics and Drive System (IJPEDS), vol. 10, pp. 10-18, 2019.

[3] Bapayya Naidu Kommula and Venkata Reddy Kota, "Mathematical Modeling and Fuzzy Logic Control of a Brushless DC Motor Employed in Automobile and Industrial Applications," IEEE First International Conference on Control, Measurement and Instrumentation, pp. 1-5 2016.

[4] A. H. Ahmed, et al., "Comparison between fuzzy logic and pi control for the speed of bldc motor," International Journal of Power Electronics and Drive System (IJPEDS), vol. 9, pp. 1116-1123, 2018.

[5] G. G. R. Sekhar and B. Banakar, "Solar PV fed non-isolated DC-DC converter for BLDC motor drive with speed control," Indonesian Journal of Electrical Engineering and Computer Science, vol. 13, pp. 313-323, 2019.

[6] C. C. Soon, et al., "Controllers Capabilities with Computational Tuning Algorithm in Nonlinear Electro-Hydraulic Actuator System," Journal of Advanced Research in Fluid Mechanics and Thermal Sciences, vol. 52, pp. 148-160, 2018.

[7] N. H. Jabarullah, et al., "Maximum Power Point Tracking in PV Device: Material, Efficiency and Models to Supply Non-Linear DC Power Supply," Journal of Advanced Research in Fluid Mechanics and Thermal Sciences, vol. 53, pp. 157-164, 2019.

[8] R. Arulmozhiyal and R. Kandiban, "Design of fuzzy PID controller for brushless DC motor," 2012 InternationalConference on Computer Communication and Informatics, pp. 1-7, 2012.

[9] Blessy, et al., "Modeling and controlling of BLDC motor based fuzzy logic," International Conference on Information Communication and Embedded Systems (ICICES2014), pp. 1-6, 2014.

[10] Shamseldin, et al., "Speed control of BLDC motor by using PID control and self-tuning fuzzy PID controller," 15th International Workshop on Research and Education in Mechatronics (REM), pp. 1-9, 2014.

[11] Krishnan, et al., "Control of BLDC motor based on adaptive fuzzy logic PID controller," 2014 International Conference on Green Computing Communication and Electrical Engineering (ICGCCEE), pp. 1-5, 2014.

[12] M. Akhila and P. Ratnan, "Brushless DC motor drive with regenerative braking using adaptive neuro based fuzzy inference system," 2016 International Conference on Electrical, Electronics, and Optimization Techniques (ICEEOT), pp. 748-751, 2016.

[13] Xiong, et al., "Research on Speed Control System of Brushless DC Motor Based on Neural Network," 2015 8th International Conference on Intelligent Computation Technology and Automation (ICICTA), pp. 761-764, 2015.

[14] M. A. Ibrahim, et al., "Optimal PID controller of a brushless DC motor using genetic algorithm," International Journal of Power Electronics and Drive System (IJPEDS), vol. 10, pp. 822-830, 2019.

[15] N. N. Baharudin and S. M. Ayob, "Brushless DC Motor Speed Control Using Single Input Fuzzy PI Controller," International Journal of Power Electronics and Drive System (IJPEDS), vol. 9, pp. 1952-1966, 2018.

[16] R. Krishnan, "Permanent magnet synchronous and brushless DC motor drives," Book, CRC press, 2009.

[17] H. R. Khoei and E. F. Shahraki, "'Fuzzy logic based direct power control of induction mot drive," Bulletin of Electrical Engineering and Informatics, vol. 5, pp. 296-306, 2016.

[18] Sevil Ahmed, Andon Topalov, Nikolay Dimitrov and Eugene Bonev, “ Industrial Implementation of a Fuzzy Logic Controller for Brushless DC Motor Drives using the PicoMotion Control Framework," IEEE 8th International Conference on Intelligent Systems, 978-1-5090, 2016.

[19] Ozek, et al., "A software tool: Type-2 fuzzy logic toolbox," Computer Applications in Engineering Education, vol. 16, pp. 137-146, 2008.

[20] H. Ying, "Fuzzy control and modeling: analytical foundations and applications," Wiley-IEEE Press, 2000.

[21] Passino, et al., "Fuzzy control," Menlo Park, CA: Addison-wesley, vol. 42, 1998.

[22] G. J. Klir and B. Yuan, "Fuzzy sets and fuzzy logic: theory and applications," New Jersey: Prentice Hall PTR, vol. 574, 1995.

[23] Ozek, et al., "A software tool: Type-2 fuzzy logic toolbox," Computer Applications in Engineering Education, vol. 16, pp. 137-146, 2008.

[24] Mendel, et al., "Interval type-2 fuzzy logic systems made simple," IEEE transactions on fuzzy systems, vol. 14, pp. 808-821, 2006.

[25] Alireza Sadeghian, Jerry M. Mendel and Hooman Tahayori,“ Advances in Type-2 Fuzzy Sets and Systems,” Book, Springer, New York, Press, 2013. 


\section{BIOGRAPHIES OF AUTHORS}

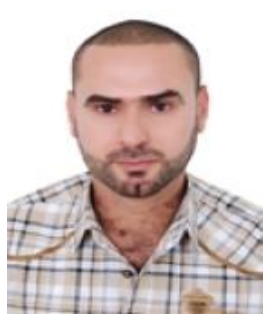

Hayder Yousif Abed: Was born in Baghdad, Iraq, in 1974. He received his B.Sc. in the College of Electrical Engineering from the University of Technology, Iraq, respectively in 2006. He received his M.Sc in 2012 from the University of Technology, Iraq. He is now a PhD student of University of Technology, Iraq. He research interests are power electronic.

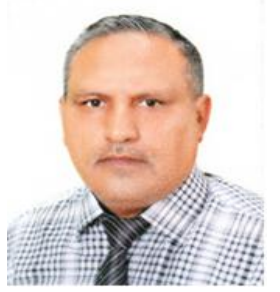

Abdulrahim Thiab Humod: Was born in Baghdad, Iraq, in 1961. He received his B.Sc. in the Department of Electrical and Electronic Engineering, Military engineering college, Iraq, respectively in 1984. He received his M.Sc in 1990 (control and guidance) from the Military engineering college, Iraq. His Ph.D. from Military engineering college (control and guidance) He is now a Asst. Professor in University of Technology, Iraq. He research interests are control and guidance.

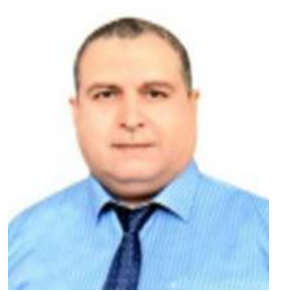

Amjad J. Humaidi: He received his B.Sc. and M. Sc. degrees in Control engineering from AlRasheed College of Engineering and Science the University of Technology, Baghdad, Iraq, in 1992 and 1997, respectively. He received his Ph.D. degree from university of technology in 2006 with specialization of control and automation. He is presently deputy dean of control and system engineering department. His fields of interest include advanced control (adaptive control, backtepping control, nonlinear optimal control, nonlinear observers, and active rejection control), intelligent control, optimization and identification 